Finite Element Analysis of Cracking and Delamination of Concrete Beam due to Steel Corrosion

YG Du, A H C Chan, L A Clark, XT Wang, F Gurkalo and S Bartos

Details of authors

Dr. Yingang Du

Senior Lecturer in Civil Engineering

Department of Engineering and Built Environment

Anglia Ruskin University

Chelmsford CM1 1SQ

United Kingdom

Tel: $\quad 08451963945$

E-mail: yingang.du@anglia.ac.uk

Prof. Andrew H C Chan

Professor in Computational Engineering

School of Civil Engineering

The University of Birmingham

Birmingham, B15 2TT

United Kingdom

Tel: 0121-4145100

E-mail: a.h.chan@bham.ac.uk

Prof. Leslie A Clark

Emeritus Professor of Structural Engineering

School of Civil Engineering

The University of Birmingham

Birmingham, B15 2TT

United Kingdom

E-mail: 1.a.clark@bham.ac.uk

Prof. Xintang Wang

Department of Civil Engineering

Ningbo University

Ningbo, China

Email:wxt196322@126.com

Mr. Filip Gurkalo

PhD Student in Civil Engineering

Department of Engineering and the Faculty of Civil Engineering

Built Environment

Anglia Ruskin University

Chelmsford CM1 1SQ

Zagreb, Franje Hermana 16E,

United Kingdom

Republic of Croatia

Email: bartos@gmail.com

E-mail: filip.gurkalo@anglia.ac.uk

Number of Figures $16 \quad$ Numbers of Table 2 


\title{
Finite Element Analysis of Cracking and Delamination of Concrete Beam due to Steel Corrosion
}

\author{
Yingang Du, A H C Chan, L A Clark, X T Wang and S Bartos
}

\section{Introduction}

Steel corrosion is one of the most dominant causes for the premature degradation of reinforced concrete structures. It has been a topic of widespread interest to those concerned with the service performance and residual life of existing concrete structures. Although the collapse of reinforced concrete structures directly as a result of steel corrosion has rarely been reported, maintenance of these deteriorated structures has been a heavy burden on owners and users of such structures.

One of the principal effects of steel corrosion on structures is the cracking of concrete, which is caused by the volumetric expansion of corroded steel bars. As an electrochemical process initiated by concrete carbonation and/or chloride intrusion, corrosion of a steel bar in concrete involves both dissolution of iron ions from bar surface and transformation of the dissolved metal into corrosion products, i.e., rusts. Some of these rusts may possibly migrate into any voids inside the concrete, and even permeate the concrete cover and remain on the concrete surface as stains, which do not damage the integrity of the concrete. However, other rusts might accumulate between the corroding bar and its surrounding concrete. Since the rusts occupy a larger volume than their parent metal, a radial expansion of a corroding bar would take place around its circumference, which causes a hoop tension and radial compression strains within the surrounding concrete. As corrosion of a steel bar continues both hoop tension and radial compression strains of concrete increase. Once the maximum tensile strain of the concrete due to its hoop and radial strains exceeds its deformation capacity, cracking, spalling and even delamination, of concrete cover can occur.

Cracking of concrete due to steel corrosion has substantial influences on performance and safety of a concrete structure. It not only affects structural aesthetics and serviceability, but also accelerates the corrosion process of steel bars by providing ample oxygen and water through the developed cracks [1], which in turn promotes the further development of cracks in the concrete. In addition, the cracking and, in particular, the delamination of concrete cover can impair the bond between corroded bar 
and its surrounding concrete and decrease the effective sectional area of structural members. As a result, it will very likely alter the mechanical behaviour of a structure and may even reduce its residual capacity and service life.

Over the past decades a number of experimental investigations have been conducted to study the effect of corrosion on both performance and cracking of concrete structures[214]. In these investigations, the corrosion of a steel bar in the concrete was reproduced artificially either by applying an internal pressure or conducting accelerated corrosion tests. Both the occurrence of the first cracks and their further development on the concrete surface were monitored and recorded externally. On basis of the experimental results, it was found that internal pressure and/or amount of corrosion required for cracking almost increase linearly with the thickness of concrete cover. Owing to corrosion of multiple bars, cracks occur not only on the external surface of the concrete along the longitudinal corroded bars, but also between two adjacent corroded bars, which eventually causes the delamination of concrete cover, as typically shown in Figure 1. However, the magnitudes of the internal pressure or amount of corrosion for cracking were less consistently reported by different researchers because of the different concrete mixes and different testing techniques adopted. In addition, the above experimental results are mainly based on the external observation of the physical specimen. They were unable to reveal both initiating mechanism and propagation process of the corrosion-induced cracks in the concrete.

As a result, finite element method was brought into this research field, and facilitated an effective tool to study the corrosion - induced cracks in the concrete [15-21]. In these FE analyses, reinforced concrete beams or slabs were idealised as three or two dimensional analytical models. The expansive behaviour of corrosion products was modelled either as an internal pressure or a prescribed displacement or a volumic expansion of the joint interface element between concrete and steel bar. According to FE results, it has been found that the cracking of concrete initiates and develops as a result of an increase of the radial expansion of corroding bars. If the permeation of corrosion products from a corroding bar into its surrounding concrete cover and into the developed cracks were taken into account, both critical amount of corrosion for concrete cracking and the width of concrete cracks could be well estimated [21]. Otherwise, the FE results would under-estimate the above critical value [15, 17]. 
However, most of the analytical results reported so far were obtained using individually developed finite element package, and were validated using galvanostatic experimental results, which actually differ from those in real world of corrosion damaged concrete structure [21]. In particular, little attention has been paid to the engineering interpretation of FE results and the effect of key parameters of a concrete beam on its cracking and delamination.

Hence, this paper aims to discover the mechanism of cracking and delamination of concrete beam due to steel corrosion and to study its variation with the main parameters, i.e. bar diameter, concrete cover and bar clear distance using the commercial software package- LUSAS[22]. A series of reinforced concrete beams were idealised as a 2-D model via its cross-section. The corrosion of steel bars in concrete beams was simulated using an increasing radial expansion. The FE analytical results are validated using the experimental results of corroded concrete beams, before their engineering implications are summarised.

\section{Research Significance}

In addition to corrosion stains, cracks on the concrete surface along a corroded steel bar are another sign of corrosion of steel bars embedded in concrete members, which not only affects external appearance and serviceability of structures, but can also impair their residual capacity and service life.

An improved understanding of the initiating mechanism, development and controlling parameters of beam cracking would help design engineers to minimise the risk of corrosion cracks occurring in new structures. Particularly, it would assist practising engineers in their selection of the appropriate management strategy for corroded structures.

\section{Analytical Model and Methods}

Concrete beams that were analysed in this work were assumed to have rectangular cross-sections, be singly reinforced using four round steel bars with the same diameter, and be subjected to corrosion of the four steel bars simultaneously.

It was noted that both cracking and delamination of concrete beams due to steel corrosion are mainly caused by the radial expansion of corroded steel bars. The main 
purpose of this research was to understand the mechanism of initiation and development of beam cracking with particular reference to the influences of the relevant parameters. Therefore, the above three dimensional (3-D) reinforced concrete beams were idealised as two-dimensional (2-D) analytical models via their cross sections. Furthermore, taking into account of both symmetry of a beam section about its central line and the assumption that its four steel bars had the same diameter and corroded simultaneously, only one half of the beam cross section was taken as the analytical model, as shown in Figure 2.

The vertical symmetrical line of the beam section was assumed to be restrained against rotation and horizontal displacement, but its other three sides were free. Each steel bar with a round circle of circumference within the beam section was modelled as a polygon with its 64 nodes equally distributed around the bar 'circumference' and mechanically pinned. The radial expansive behaviour of corroded steel bars was modelled by an increasing radial uniform displacement that takes place simultaneously at each of these nodes around each bar, as shown in Figure 2. Such a radial expansion actually is imposed on to the internal surface of concrete cover around each bar and subjected confinement from surrounding cover concrete before its full cracking.

Three key design parameters, i.e., bar diameter, bar clear distance and concrete cover, as indicated in Figure 2, which affect the corrosion cracking of concrete beams with the given properties of steel and concrete, were considered analytically,. As summarised in Table 1, the bar diameters of concrete beams were taken as $d=8,16,20,25,32,40,45$, 50, 58 and $65 \mathrm{~mm}$, the bar clear distances were $s=20,40,45,50,60,70,80,90$ and 100 $\mathrm{mm}$, and the concrete covers were $c=10,25$ and $35 \mathrm{~mm}$. The depth and breadth of these reinforced concrete beams were consequently in the ranges from 480 to $540 \mathrm{~mm}$ and from 160 to $450 \mathrm{~mm}$, respectively, to accommodate the above parameters. It should be pointed out that some of the bar diameters, such as $40 \mathrm{~mm}$ and $65 \mathrm{~mm}$, etc. are not commonly used in practice, but were included in the FE analysis to gain more overall understanding of the effect of the bar diameter on the beam cracking.

The analysis of the cracking of a beam section due to corrosion of reinforcement was conducted using finite element software - LUSAS version 14.1 for its analytical capabilities of modelling cracking, crushing and characteristic behaviour of the concrete in a consistent and robust manner. The half of the beam section was further meshed into 
a number of quadrilateral plane elements with 8 nodes with the fine mesh adopted for the concrete nearby the circumference of steel bar, as shown in Figure 3. Here, three meshing regimes were first included in the analysis of typical beam section with a diameter of $20 \mathrm{~mm}$ of four bars at a clear distance of $40 \mathrm{~mm}$ and covered by $25 \mathrm{~mm}$ concrete cover for the purpose of checking its mesh dependency.

The beam concrete was simulated using the Concrete Model 94 (nonlinear, plastic, Multi-crack concrete) as defined in the LUSAS Manuals[22]. This model is a plasticdamage-contact model, in which damaged planes form according to a principal stress criterion and then develop as embedded rough contact planes. The basic softening curve in the model is dominated via a fracture-energy controlled softening curve[22].

Both compressive strength $f_{\text {cu }}$ and tensile strength $f_{\mathrm{t}}$ of the concrete adopted the test data of $31.3 \mathrm{~N} / \mathrm{mm}^{2}$ and $2.83 \mathrm{~N} / \mathrm{mm}^{2}$, respectively, as reported by Clark and Saifullah[5]. Both elastic modulus and Poisson's ratio were taken as $E_{\mathrm{c}}=30687 \mathrm{~N} / \mathrm{mm}^{2}$ and $\rho=0.2$. Both the strain to peak compressive stress $\varepsilon_{0}$ and ultimate compressive strain $\varepsilon_{\text {cu }}$ as 0.002 and 0.0035. The rest data adopted the values as recommended in LUSAS Manuals[22]

For the purpose of clarifying the initial mechanism and development of beam cracking due to steel bar corrosion, the amount of radial expansion determined using the FE model was deemed to be equivalent to the amount of corrosion that was needed for that type of beam cracking using Equation 1[15].

$$
Q_{\text {corr }}=\frac{2 \Delta}{R_{0}(\mu-1)}
$$

Where, $Q_{\text {corr }}=1-\left(\frac{R_{c}}{R_{0}}\right)^{2}$ is the amount of corrosion (\%), $R_{0}$ is the radius of the noncorroded bar, $R_{c}$ is the remaining radius of a corroded bar, $x=\left(R_{0}-R_{c}\right)$ is the attack penetration of a corroded bar, $\Delta=(\mu-1)\left(R_{0}-R_{c}\right)$ is the net radial expansion of a corroded bar in term of radial expansion (mm), as prescribed in the finite element analysis. $\mu=$ the coefficient of volume expansion of corrosion products [15]

However, it should be noted that the amount of corrosion for concrete cracking calculated using the radial expansion from a finite element is generally much smaller than those measured from corrosion tests. This is because a significant amount of 
corrosion products in corrosion tests diffused into the concrete pores and dissipated out of the concrete. Hence, the issue of the diffusion of corrosion products into concrete pores has to be considered whenever extrapolating laboratory data to field conditions and whenever using analytical corrosion models to predict real structural behaviour[15].

Furthermore, it was assumed that corrosion expansion around a bar circumference is uniform and the rate of corrosion during the period of structural service is constant. Therefore, the larger is the calculated radial expansion, the greater is the amount of corrosion that is needed for that particular type of beam cracking, and the latter that type of cracking would occur.

It should be pointed out that, in practice, the corrosion of a steel bar is not always uniform but varies around its sectional circumference and along its longitudinal length, which does affect the cracking of the concrete, as addressed previously [15]. The different steel bars in a concrete beam may corrode at different rates, which would affect the cracking, including cracking initiation, development mechanism and cracking patter of a concrete beam. For simplicity and for the specified research purposes, however, the corrosion of different steel bars in the concrete beams was assumed to be uniform and simultaneous. It was simulated with the same uniform radial expansion (displacement) incrementally applied to each of the nodes of the two steel bars.

\section{FE Analytical Results and Discussions}

\subsection{Mechanism of Cracking and Delamination of Beam due to Steel Corrosion}

Taking a concrete beam with $20 \mathrm{~mm}$ diameter bars, $40 \mathrm{~mm}$ clear distance and $25 \mathrm{~mm}$ concrete cover as a typical example, the initiating mechanism and developing progress of beam cracking due to steel corrosion in term of radial expansion are shown in Figure 4. Here the only part of beam section that have been cracked due to steel corrosion was included for more clear demonstration with the rest part of un-cracked beam section excluded, as shown in Figure 4.

Figure 4 shows that, as corrosion of the steel bars in terms of radial expansion increased from $0.0007 \mathrm{~mm}$ to $0.0049 \mathrm{~mm}$, the cracking of the concrete beam throughout its section experienced four different types or stages: Internal Cracking, Internal Penetration, External Cracking (HS) and External Cracking (VB). Initially, no cracks 
could be found for a small radial expansion. However, once the radial expansion reached at $0.0007 \mathrm{~mm}$, cracks first appeared on the internal surface of the concrete cover and were distributed equally around and nearby each bar, which is defined as Internal-Cracking. As the radial expansion increased to about $0.0032 \mathrm{~mm}$, the cracks already formed propagated through the concrete between two steel bars and joined up with each other, which is referred to as Internal Penetration or delamination. As the radial expansion further increased to $0.045 \mathrm{~mm}$ and $0.0049 \mathrm{~mm}$, cracks eventually penetrated the $25 \mathrm{~mm}$ thick concrete cover and progressed horizontally to beam side surface (HS) and vertically to beam bottom surfaces (VB), which were referred to as External Cracking (HS) and External Cracking (VB), respectively.

It should be pointed out that the above analytical results shown in Figure 4 are less consistent with those reported by Toongoenthong and Maekawa in terms of dominance of external cracks [21]. In Toongoenthong and Maekawa's results, both external cracks (VB) and internal penetration (IP) were included in their Figure 8 for the same amount of mass loss of $4.63 \%$ with creep and buffer capacity. However, the above Figure 4 shows that the internal penetration takes place prior to the external cracking. This is because the different software packages and different configuration of the beam sections were used in the analysis. Toongoenthong and Maekawa used specially developed software to analyse the beam section with two $16 \mathrm{~mm}$ diameter bar, $30 \mathrm{~mm}$ concrete cover and 58mm bar spacing. The Figure 4 in this paper was obtained using commonly used LUSAS package conducted on a beam section with four $20 \mathrm{~mm}$ diameter of bars, $25 \mathrm{~mm}$ concrete and $40 \mathrm{~mm}$ bar spacing.

It should be pointed out that since the permeation of corrosion products from the 'corroding bars' into the voids of their surrounding concrete were not taken into account, the above calculated radial expansion using FE analysis would well understate the amount of corrosion for beam cracking. However, this is not the case to be investigated in this paper.

\subsection{Mesh Dependency}

Also taking a concrete beam with $20 \mathrm{~mm}$ diameter bars, $40 \mathrm{~mm}$ clear distance and 25 $\mathrm{mm}$ concrete cover as an example, the cracking and delamination of beam section under three different meshing regimes, as shown in Figure 3, are shown in Figure 5. 
It is clear that both types of beam cracking due to steel corrosion and the corresponding radial displacement required for the same types of beam cracking don't vary too much with the different meshing regimes of beam section. In other words, the FE analytical results don't depend on the meshing regime. As a result, in the subsequent analysis would be conducted using meshing 2 .

The FE analytical results also indicated that, for all reinforced concrete beams considered, the radial expansion that was required for Internal Cracking was the smallest and consequently Internal Cracking always occurred first. As summarized in Figure 6, however, the radial expansion required for Internal Penetration, External Cracking (HS) and External Cracking (VB) varies significantly with the key parameters of concrete beam, i.e., bar clear distance, cover thickness and bar diameter. In other words, the time when the Internal Penetration i.e., delamination of concrete cover, i.e. Internal Penetration, occurs or when the cracks can be observed externally on beam surfaces, i.e.; either External Cracking (HS) or External Cracking (VB), depends on the size of its cross section, the thickness of concrete cover, the number and diameter of steel bars, as discussed below.

\subsection{Effect of Bar Clear Distance on Beam Cracking}

The bar diameter was kept at $20 \mathrm{~mm}$. The effect of bar clear distance, in terms of a ratio $s / c$ of bar clear distance to concrete cover, on beam cracking is shown in Figures 7 to 9 for concrete covers of 10, 25 and $35 \mathrm{~mm}$, respectively. The radial expansions to cause Internal Cracking, Internal Penetration, External Cracking (HS) and External Cracking (VB) are shown in each Figure.

It is obvious that the bar clear distance does not affect the corrosion for the internal cracking of a concrete beam. For the $20 \mathrm{~mm}$ diameter bar and for the three different concrete covers of $10 \mathrm{~mm}, 20 \mathrm{~mm}$ and $35 \mathrm{~mm}$, the radial expansion to cause Internal Cracking of the concrete beam was a constant of $0.0007 \mathrm{~mm}$ for all the ratios of $s / c$.

Figures 7 to 9, however, indicate that the bar clear distance dominates the corrosion for the delamination of concrete cover. The radial expansion required for Internal Penetration increases almost linearly with the ratio $s / c$ of bar clear distance to concrete cover, irrespective of whether the concrete cover was $10 \mathrm{~mm}, 25 \mathrm{~mm}$ or $35 \mathrm{~mm}$. For a concrete beam with a $25 \mathrm{~mm}$ concrete cover, for example, as the ratio s/c decreased 
from 4.0 to 0.8 due to a reduction of bar clear distance, the radial expansion for Internal Penetration reduced from 0.0123 to $0.0016 \mathrm{~mm}$. In other words, the smaller is the bar clear distance in term of the ratio $s / c$, the less is the radial expansion required to cause Internal Penetration and, therefore, the earlier the delamination of concrete cover would occur.

In particular, when the ratio $s / c$ is less than about 2.2, the radial expansion for Internal Penetration became smaller than those for External Cracking (HS) and External Cracking (VB). In other words, the delamination of concrete cover very likely occurs before corrosion cracks can be seen externally on the beam surface. This is one of the worst scenarios for the management of deteriorated concrete structures with corroded steel bars.

When the ratio $s / c$ exceeded about 2.2, on the other hand, the radial expansion to cause Internal Penetration became greater than those to cause External (HS) and External Cracking (VB). In other words, if bar clear distance is larger than about 2.2 times the concrete cover, the delamination of concrete cover could be prevented from happening in a structure with corroding steel bars before the appearance of surface cracking.

As shown in Figures 7 to 9, as bar clear distance increases in term of the ratio of $s / c$ from 0.6 to 10, overall the radial expansions for External Cracking (HS) and External Cracking (VB) decrease, although there are some scatter points. In other words, the larger the bar clear distance, the earlier the cracks can be observed on beam surface. However, such effect is less significant, compared with those on the beam Internal Penetration.

In summary, bar clear distance dominates the corrosion to cause Internal Penetration. The radial expansion or amount of corrosion almost linearly increases with bar clear distance. The smaller is the bar clear distance, the earlier is the cracking of the concrete between adjacent corroded bars and the later the cracks that can be seen on a beam's surfaces externally. This sequence of cracking makes the maintenance and management of corroded concrete structures more challenging in practice.

\subsection{Effect of Concrete Cover on Beam Cracking}


For concrete beams with $20 \mathrm{~mm}$ diameter bars and a clear distance of $20 \mathrm{~mm}$, 40mm, $60 \mathrm{~mm}, 80 \mathrm{~mm}$ and $100 \mathrm{~mm}$, the effect of concrete cover on beam cracking is shown in Figures 10 to 13, respectively, for Internal Cracking, External Cracking (HS) and External Cracking (VB) and Internal Penetration.

Figure 10 indicates that the radial expansion for internal cracking doesn't vary with the magnitudes of both concrete cover and bar clear distance, which is consistent with the results shown in Figures 7 to 9. In other words, both the thickness of concrete cover and the clear distance between the corroding bars do not affect the amount of corrosion for internal cracking of beam section. It has to be noted that, however, in practical engineering, the thickness and density of concrete cover would affect the initiation of corrosion of steel bars, which in turn influences the internal cracking of concrete beam. A thick and dense concrete cover would delay the initiation of steel corrosion and therefore postpone the internal cracking of beam section.

Figures 11 and 12, however, show that concrete cover dominates External Cracking (HS) and External Cracking (VB) of concrete beams. The radial expansion to cause External Cracking (HS) or External Cracking (VB) increases almost linearly with an increase of concrete cover, irrespective of bar clear distance. For $20 \mathrm{~mm}$ diameter bars and $40 \mathrm{~mm}$ bar clear distance, an increase of concrete cover from $10 \mathrm{~mm}$ to $35 \mathrm{~mm}$ causes the radial expansion for External Cracking (HS) and External Cracking (VB) to rise from $0.0016 \mathrm{~mm}$ to $0.0064 \mathrm{~mm}$ and from $0.0016 \mathrm{~mm}$ to $0.0065 \mathrm{~mm}$, respectively. Hence, an increase of concrete cover increases the radial expansion for External Cracking (HS) and External Cracking (VB) and therefore delays the occurrence of the cracks occurring on beam surfaces

Since an increase of concrete cover from $10 \mathrm{~mm}$ to $35 \mathrm{~mm}$ causes a decrease of the ratio s/c, the effect of concrete cover on Internal Penetration of concrete beams depends on bar clear distance, as shown in Figure 13. It is clear that, as long as bar clear distance is such that the ratio $s / c$ is less than about 2.2, the concrete between the adjacent corroded bars is first penetrated, and, therefore, concrete cover has little influence on Internal Penetration of concrete beams. As shown in Figure 13, for a bar clear distance of $20 \mathrm{~mm}$, as concrete cover increases from $10 \mathrm{~mm}$ to $35 \mathrm{~mm}$, the ratio $\mathrm{s} / \mathrm{c}$ reduces from 2.0 to 0.57 , which is less than 2.2. Therefore, the radial expansion to cause Internal Penetration is essentially constant at $0.0016 \mathrm{~mm}$. 
In contrast, once bar clear distance is such that the ratio $s / c$ is larger than about 2.2, the corrosion cracks would penetrate the concrete cover first and eventually reach the beam's surface. As a result, concrete cover has a substantial influence on the radial expansion for Internal Penetration. As shown in Figure 13, for a bar clear distance of $100 \mathrm{~mm}$, as concrete cover increases from $10 \mathrm{~mm}$ to $35 \mathrm{~mm}$, the ratio s/c decreases from 10.0 to 2.86, which is larger than 2.2. As a result, the radial expansion to cause Internal Penetration is approximately halved as the cover increases. In other words, for a concrete beam with a large bar clear distance, an increase of concrete cover increases the likelihood of the delamination of concrete cover due to steel corrosion.

For an intermediate bar clear distance of $40 \mathrm{~mm}$, the ratios of s/c are equal to 4.0, 1.6 and 1.16 for concrete covers of $10 \mathrm{~mm}, 25 \mathrm{~mm}$ and $35 \mathrm{~mm}$, respectively. As a result, the radial expansion to cause Internal Penetration is essentially constant at $0.0031 \mathrm{~mm}$ for the two smaller ratios of $s / c$, but about $20 \%$ greater for the largest ratio of $s / c=4.0$ corresponding to $10 \mathrm{~mm}$ concrete cover.

It should be pointed out that, however, in a practical engineering structure, after the cracks occur on the concrete surface, i.e., Cracking (HS) and External Cracking (VB), some corrosion products would permeate through the developed cracks and stay on the concrete surface as stains, instead of building more expansive pressure for the further cracking of the concrete between the corroding bars. In other words, after the Cracking (HS) and External Cracking (VB), the Internal Penetration might not necessarily take place in practical structure. On other hand, however, if some impropriate measures, such as filling up the developed cracks or covering the cracked concrete using a new concrete to repair the corrosion-damaged concrete, the case would become worse with the Internal Penetration occurring following after the Cracking (HS) and External Cracking (VB).

When the above observations and discussions are combined it appears that concrete cover controls the occurrence of the first cracks that can be developed on the external surface of concrete beams. It affects the Internal Penetration only if the cover implies a ratio $s / c$ in excess of a value in the range of 2.0 to 2.86 or some inproporiate measures were taken to repair corrosion damaged concrete. Hence, it again appears that a ratio s/c of about 2.2 is a critical value. 


\subsection{Effect of Bar Diameter on Beam Cracking}

For concrete beams with a bar clear distance of $40 \mathrm{~mm}$ and a concrete cover of $25 \mathrm{~mm}$, the effect of bar diameter on their corrosion cracking is shown in Figure 14.

It is clear that a change of bar diameter dominates Internal Cracking. The radial expansion to cause Internal Cracking increases almost linearly with bar diameter. This is due to the fact that Internal Cracking occurs approximately when the circumferential tensile strain $\varepsilon_{\mathrm{cr}}$ of the concrete due to the radial expansion $\Delta$ of a corroding bar with a diameter of $d$ equals the tensile strain capacity of the concrete $\varepsilon_{\mathrm{ct}}$, i.e.,

$$
\varepsilon_{c r}=\frac{\pi(d+2 \Delta)-\pi d}{\pi d}=\frac{2 \Delta}{d}=\varepsilon_{c t}
$$

As a result, the radial expansion to cause Internal Cracking of a concrete beam is:

$$
\Delta=\varepsilon_{c t} \frac{d}{2}
$$

Since the tensile strain capacity, $\varepsilon_{\mathrm{ct}}$, varies with the type and strength the concrete only, for the given concrete, the radial expansion $\Delta$ for Internal Cracking of concrete beam does vary linearly with its bar diameter.

Figure 14 also shows that, whilst the radial expansion to cause Internal Penetration is less dependent on bar diameter, those required for both External Cracking (HS) and External Cracking (VB) vary significantly with bar diameter. As demonstrated in Figure 15, for the concrete beams with the developed cracks in the concrete between corroded bars, the bottom concrete cover can be assumed to be cantilevered at its side concrete cover. An increase of bar diameter increases the lever arm of the resultant forces caused by corrosion expansion to the un-cracked side concrete cover. As a result, the radial expansion to cause External Cracking (HS) decreases as bar diameter increase. Similarly, Figure 14 also can be used to demonstrate the effect of bar clear distance on External Cracking (HS), as long as two steel bars are assumed to have the ` of $d_{1}=d_{2}=d$, but with two different clear distances of $s_{1}$ and $s_{2}$. An increase of bar clear distance also increases the lever arm of the corrosion-induced resultant forces and, therefore, decreases the radial expansion for External Cracking (HS), as shown in Figures 7 to 9 . 
Following the External Cracking (HS) due to a smaller radial expansion, as shown in Figure 14, some hoop tensile strain is released and more corrosion needs to be built up for External Cracking (VB). Therefore, the radial expansion to cause External Cracking (VB) rises as bar diameter increases, as shown in Figure 14.

Figure 14 also illustrates that, if bar diameter is less than about $16 \mathrm{~mm}$, the corrosion cracks may likely be observed first on the bottom surface of concrete beams, i.e., External Cracking (VB). Otherwise, they may first on the side surfaces of concrete beams, i.e., External Cracking (HS).

In summary, bar diameter hardly affects corrosion for Internal Penetration, but it dominates and alters the radial expansion for Internal Cracking almost linearly. In addition, an increase of bar diameter slightly decreases the radial expansion to cause External Cracking (HS) but increases those to External Cracking (VB).

\section{Validation of FE Analytical Solutions}

An experimental investigation was conducted independently on reinforced concrete beams to study the effect of steel corrosion on their mechanical behaviour as well as concrete cracks $[23,24]$. These concrete beams had the same cross section of $150 \mathrm{~mm}$ wide by $200 \mathrm{~mm}$ deep and the same links of $8 \mathrm{~mm}$ diameter bar, but with different configurations of steel bars, which were subjected to an accelerated corrosion. As summarised in Table 2, the nominal size of the concrete cover to the steel bars was 20 $\mathrm{mm}$. Due to the top-casting of the concrete, however, the actual concrete cover to the top steel bars of the beams C124 and C162 were $17 \mathrm{~mm}$ and $25 \mathrm{~mm}$, respectively.

Either the bottom tension bars or the top compression bars within the midspan region of these simply supported beams were artificially corroded to simulate the deterioration process that may occur within practical corroded structures. During the period of either 2 or 4 months of corrosion under direct currents of $0.35,0.45$ and $0.90 \mathrm{~mA} / \mathrm{cm}^{2}$, the occurrence of the first cracks on beam surfaces as well as their further development were externally observed with the widths of the cracks measured using a crack comparator. After the corrosion of steel bars reached the anticipated levels, the cracks on the beam surfaces were highlighted using black pen and photographed, as tabulated in Table 2, which was followed by loading tests on the corroded beams to investigate the residual strength and ductility of corroded beams. At the end of the tests, the 
concrete covers of the corroded bars were removed from tested beams to check the internal penetration in the concrete between corroded bars, before the corroded bars were taken out of the beams to measure the amount of corrosion. By combining the information from the observation of concrete cracks on beam surface and the corrosion products left in the concrete between corroded bars, the cracking pattern of the beam sections were schematically summarised in Figure 16[24].

Both Table 2 and Figure 16 indicate that all of the cracks on beam surfaces were along the corroded steel bars and always occurred in the direction where the thickness of concrete cover was smallest. For beams C124 and C162 with minimum concrete covers of $20 \mathrm{~mm}$ and $17 \mathrm{~mm}$, respectively, the corrosion cracks appeared on their side and top surfaces, respectively. This is consistent with the FE results shown in Figures 11 and 12, corresponding to the effect of concrete cover on External Cracking (HS) and (VB). Hence, the corrosion for the cracks to be externally observed on concrete surface does vary linearly with the thickness of concrete cover. Corrosion cracks would likely occur at where the thickness of concrete cover is the smallest.

For the beams T322, T163 and T164 with $46 \mathrm{~mm}$ bar clear distance and $20 \mathrm{~mm}$ concrete cover, their ratio of $s / c$ was equal to 2.3 , which is close to the critical value of 2.2 , the corrosion products were observed in the concrete between the corroded bars, after their concrete cover was removed at the end of the test. Therefore it can be assumed that the concrete between corroded bars was penetrated internally, i.e., Internal Penetration, as shown in Table 2 and Figure 16. This agreed well with Figures $\mathbf{7}$ to $\mathbf{9}$ for the case of the ratio s/c less than 2.2. Hence, if bar clear distance is less than or close to about 2.2 times of concrete cover, the cracks would be likely to propagate through the concrete between adjacent corroded bars before they could be externally observed on the concrete surface

For the beams C124, C162, T282, T122 and R122 with $86 \mathrm{~mm}$ bar clear distance and 20 $\mathrm{mm}$ concrete cover, however, since their ratios of $s / c$ were 4.3 , which are larger than the critical value of 2.2, either External Cracking (HS) or External Cracking (VB), instead of Internal Penetration, took place with corrosion cracks occurring on their surfaces. The most of the concrete between the corroded bars of the beams C124, C162, T282, T122 and R122 had fresh surface without corrosion products left, after their concrete cover were removed. This is also consistent with Figures $\mathbf{7}$ to $\mathbf{9}$ for the case of the ratio 
s/c greater than 2.2. Hence, as long as bar clear distance is not less than about 2.2 times of concrete cover, the internal penetration of the concrete between corroded bars could be prevented from happening prior to the appearance of surface cracking.

However, a minor difference between the FE analytical and experimental results should be noted. For beams with the ratio s/c larger than 2.2, Figures 7 to 9 show that External Cracking (HS) and External Cracking (VB) should be followed by Internal Penetration. However, Table 2 and Figure 16 indicate that External Cracking (HS) and External Cracking (VB) occurred without Internal Penetration. This is due to that fact that, once corrosion cracks first penetrated the cover concrete, the hoop tensile strain in the concrete was released and a significant amount of corrosion products could be dissipated through the developed cracks. Hence, in the tests, less corrosion products would be available to build up further pressure around the bars to cause subsequent Internal Penetration.

From the above comparison and discussion, it is clear that overall the FE analytical results agree well with experimental observations that were made on corroded concrete beams.

\section{Engineering Implication of FE Results}

In order to meet the requirements of structural durability, the Eurocode BS EN 1992 defines the service environment of a structure and specifies the minimum concrete cover in the range of 10 to $55 \mathrm{~mm}$ [25]. To control the cracks under service actions, rather than the cracks due to steel corrosion, BS EN 1992 gives limits on either maximum bar diameters in the range from $4 \mathrm{~mm}$ to $40 \mathrm{~mm}$ or bar spacing from $50 \mathrm{~mm}$ to $300 \mathrm{~mm}$, depending on the stress level and the allowable crack width. To ease concrete casting and ensure an adequate bond, BS EN 1992 also limits the minimum bar clear distance to either $20 \mathrm{~mm}$ or the maximum aggregate size plus $5 \mathrm{~mm}$ or the maximum bar diameter. However, BS EN1992 does not consider the implications for durability of bar spacing and clear distance.

The FE analytical results, reported in this paper and validated against experimental observation, give a very important indicator for the durability design of concrete structures and assessment of existing deteriorated structures. 
For the design of a new structure that may suffer from steel corrosion during its service life, in addition to a proper selection of concrete cover to satisfy the requirements in BE EN1992, it would be preferable for bar clear distance to be greater than 2.2 times the concrete cover in order that, if corrosion were to occur, corrosion cracks would be seen externally at an early stage of the corrosion process. However, it is recognised that it is unlikely in practice that such a requirement would take preference over the need for a small clear distance in order to control crack widths, because the latter would normally be a client requirement of the designer, and, therefore, would take precedence. Hence, an internal cracking of the concrete between the corroded bars may likely occur in the deteriorated structures with corroded steel bars.

For the assessment and management of existing corroded structures, an engineer should be aware of possible internal penetration where bar clear distance is less than 2.2 times the concrete cover, and bear in mind that an undamaged concrete surface of a structure does not necessarily mean that the structure is in a healthy state without steel corrosion.

In summary, the FE analytical results reported in this paper provide engineers with some supplementary information for durability design and assessment of concrete structures

\section{Conclusions}

- The cracking of concrete beams due to steel corrosion is caused by an increasing radial expansion of corroded steel bars. Beam Cracking develops in four stages, i.e., Internal Cracking, Internal Penetration, External Cracking (HS) and External Cracking (VB).

- The bar diameter, bar clear distance and concrete cover of a concrete beam dominate the corrosion to cause Internal Cracking, Internal Penetration, External Cracking (HS) and External Cracking (VB), respectively.

- An increase of bar diameter linearly increases the corrosion to cause Internal Cracking. The larger the bar diameter is, the later the cracks would occur on the internal surface of the concrete cover.

- An increase of bar clear distance linearly increases the corrosion to cause Internal Penetration. A small bar clear distance would be likely to cause the concrete 
between corroded bars to be cracked first, before corrosion cracks can be seen externally on the concrete surface.

- An increase of concrete cover linearly increases the corrosion to both External Cracking (HS) and (VB). A thick concrete cover would delay the occurrence of corrosion cracks on concrete surfaces.

- In particular, whether due to an increase of concrete cover or a decrease in bar clear distance, once the ratio of bar clear distance to concrete cover $s / c$ is less than 2.2, the concrete between the corroded bars may be penetrated by corrosion cracks prior to cracks being visible on a structure's surface. This is a very dangerous situation for a deteriorated structure, because, even if the structure were inspected regularly, there would be no early visual indication of deterioration.

- For assessment of deteriorated structures, particular care should be taken where bar clear distance is less than about 2.2 times of the concrete cover. An undamaged concrete surface of a structure does not necessarily mean that the structure is in a healthy state without steel corrosion.

\section{References:}

1. Tuutti K Service Life of Structures with Regard to Corrosion of Embedded Steel, ACI Special Publication, SP65-13, American Concrete Institute, pp 223-236.

2. Andrade C, Alonso C, Rodriguez $\mathbf{J}$ and Garcia M Cover Cracking and Amount of Rebar Corrosion: Importance of the Current applied Accelerated Tests, Durability of Building Materials and Components, Vol. 7, Edited by C Sjostrom, E \& FN Spon, London, 1996, pp263-273.

3. Andrade C, Alonso C, Rodriguez J, Casal J and Diez J M Relation between Corrosion and Concrete Cracking, The Residual Service Life of Reinforced Concrete Structures, Brite/Euram Project BREU CT92 0591, August 1995. 
4. Liu $\mathbf{Y}$ and Weyers $\mathbf{R}$ E Modelling the Time-to-Corrosion Cracking in Chloride Contaminated Reinforced Concrete Structures, ACI Materials Journal, V.95, No.6, November-December 1998, pp675-681.

5. Clark L A and Saifullah M Effect of Corrosion on Steel bar Bond Strength, Proceedings of $5^{\text {th }}$ International Conference on Structural Faults and Repairs, Vol. 3, Edited by Forde M, Engineering Technical Press, Edinburgh, 1993, pp113-119.

6. Al-Sulaimani G J, Kaleemullah M, Basunbul I A and Rasheeduzzafar Influence of Corrosion and Cracking on Bond Behaviour and Strength of Reinforced Concrete Members, ACI Structural Journal, Vol.87, No. 2, March-April 1990, pp220-231

7. Rasheeduzzafar, Al-Saadoun S S and Al - Gahtani A S Corrosion Cracking in Relation to Bar Diameter and Concrete Quality, Journal of Materials in Civil Engineering, Vol. 4, No. 4, November, 1992, pp327-342.

8. Williamson J S. and Clark L A Pressure Required to Cause Cover Cracking of Concrete due to Steel bar Corrosion, Magazine of Concrete Research, Vol 52, No 6, December, 2000, pp455-467

9. Morinaga S Remaining Life of Reinforced Concrete Structures after Corrosion Cracking, Durability of Building Materials and Components, Edited by Sjostrom C, Published by E \& FN Spon, 1996, pp127-137

10. Cairns J, Du Y G and Law D (2008), Structural performance of corrosiondamaged concrete beam, Magazine of Concrete Research, Vol.60, No.5, p359-370.

11. Tachibana Y., Kajikawa Y., and Kawamura M. The Mechanical Behaviours of RC Beams Damaged by Corrosion of Steel bar, Concrete Library of JSCE, No. 14, March 1990, pp. 177 188.

12. Almusallam A. A., AL-Gahtani A. S., Rauf Aziz A., Dakhill F. H. and Rasheeduzzafar Effect of Steel bar Corrosion on Flexural Behaviours of Concrete Slabs, Journal of Materials in Civil Engineering, Aug. 1996, pp. 123 127. 
13. AL-Sulaimani G. J., Kaleemullah M., Basunbul I. A. and Rasheeduzzafar Influence of Corrosion and Cracking on Bond Behaviours and Strength of Reinforced Concrete Members, ACI Structural Journal, March April 1990, pp. $220 \sim 231$.

14. Okada K., Kobayashi K., and Miyagawa T. Influence of Longitudinal Cracking due to Steel bar Corrosion on Characteristics of Reinforced Concrete Members, ACI Structural Journal, March April 1988, pp. $134 \sim 140$

15. Du Y. G., Chan A. H. C., and Clark L. A. Finite Element Analysis of the Effects of Radial Expansion of Corroded Steel bar, International Journal of Computers and Structures, Vol.84, No. 13-14, June, 2006, pp917-929.

16. Dagher $\mathbf{H} \mathbf{J}$ and Kulendran $\mathbf{S}$ Finite Element Modelling of Corrosion Damage in Concrete Structures, ACI Structural Journal V.89, No. 6, November-December 1992, pp699-708.

17. Molina F J Andrade C and Alonso C Cover Cracking as Function of Bar Corrosion: Part 2 - Numerical Model, Materials and Structures, Vol. 26, 1993, 532-548.

18. Ueda T, Sato $\mathbf{Y}$, Kakuta $\mathbf{Y}$ and Kameya $\mathbf{H}$ Analytical Study on Concrete Cover due to Reinforcement Corrosion - Towards Rational Design for Long Term Performance, Concrete Library of JSCE No.22, Mar. 1998, pp145-158

19. Tran KK, Nakamura H, Kunieda M and Ueda N, Three Dimensional Behaviour of Concrete Cracking Due to Rebar Corrosion, Journal of Procedia Engineering, 14 (2011) PP419 - 426

20. Benin AV, Semenov AS and Semenov SG, Modelling of Fracture Process in Concrete Reinforced Structures under Steel Corrosion, Journal of Achievements in Materials and Manufacturing Engineering, Vol. 39, Issue 2, 2010, pp 168 - 175

21. Toongoenthong $\mathbf{K}$ and Maekawa $\mathbf{K}$, Simulation of Coupled Corrosive Product Formation, Migration into Crack and Propogation in Reinforced Concrete Sections, Journal of Advanced Concrete Technology, Vol. 3, No.2, 2005, pp 253 -265.

22. The LUSAS User's Manual, Finite Element Analysis Ltd, Forge House, 66 High Street, Kingston Upon Thames, London, UK 
23. Du, Y G, Clark L A and Chan A H C (2007), Impact of reinforcement corrosion on ductile behaviour of reinforced concrete beams, ACI Structural Journal, Vol.104, No. 3, pp285-293.

24. Du, Y G, Effect of reinforcement corrosion on structural concrete ductility, PhD thesis, The University of Birmingham, 2001, Birmingham, B15 2TT, UK

25. British Standards Institution (2004), BS EN1992-1-1:2004: Eurocode 2: Design of Concrete Structures - Part 1-1: General rules and rules for buildings, BSI, London. 
$\underline{\mathrm{Du} \text {, et al-Beam Crack-Tables and Figures }}$

Finite Element Analysis of Cracking and Delamination of Concrete Beam due to Steel Corrosion

YG Du, A H C Chan, L A Clark, XT Wang, F Gurkalo and S Bartos

\section{List of Tables}

Table 1 Summary of Analytical Parameters

Table 2 Configurations and Surfaces Cracks of Corroded Concrete Beams 
$\underline{\mathrm{Du} \text {, et al-Beam Crack-Tables and Figures }}$

Table 1. Summary of Analytical Parameters

\begin{tabular}{|c|c|c|c|c|c|c|}
\hline $\begin{array}{l}\text { Analytical } \\
\text { Parameter }\end{array}$ & $\begin{array}{c}\text { Bar } \\
\text { Diameter } \\
\mathrm{d}(\mathrm{mm})\end{array}$ & $\begin{array}{c}\text { Bar } \\
\text { Distance } \\
\mathrm{s}(\mathrm{mm})\end{array}$ & $\begin{array}{c}\text { Concrete } \\
\text { Cover } \\
\mathrm{c}(\mathrm{mm})\end{array}$ & $\begin{array}{c}\text { Ratio of } \\
\text { Distance to } \\
\text { Cover s/c }\end{array}$ & $\begin{array}{l}\text { Width of } \\
\text { Section } \\
\text { B (mm) }\end{array}$ & $\begin{array}{l}\text { Depth of } \\
\text { Section } \\
\mathrm{H}(\mathrm{mm})\end{array}$ \\
\hline \multirow{10}{*}{$\begin{array}{l}\text { Effect of } \\
\text { Bar } \\
\text { Diameter } \\
\quad(d)\end{array}$} & 8 & \multirow{10}{*}{40} & \multirow{10}{*}{25} & \multirow{10}{*}{1.6} & 202 & 483 \\
\hline & 16 & & & & 234 & 491 \\
\hline & 20 & & & & 250 & 495 \\
\hline & 25 & & & & 270 & 500 \\
\hline & 32 & & & & 298 & 507 \\
\hline & 40 & & & & 330 & 515 \\
\hline & 45 & & & & 350 & 520 \\
\hline & 50 & & & & 370 & 525 \\
\hline & 58 & & & & 402 & 533 \\
\hline & 65 & & & & 430 & 540 \\
\hline \multirow{19}{*}{$\begin{array}{c}\text { Effect of } \\
\text { Bar } \\
\text { Clear } \\
\text { Distance } \\
(s)\end{array}$} & \multirow{19}{*}{20} & 20 & \multirow{5}{*}{10} & 2.0 & 160 & 480 \\
\hline & & 40 & & 4.0 & 220 & 480 \\
\hline & & 60 & & 6.0 & 280 & 480 \\
\hline & & 80 & & 8.0 & 340 & 480 \\
\hline & & 100 & & 10.0 & 400 & 480 \\
\hline & & 20 & \multirow{9}{*}{25} & 0.8 & 190 & 495 \\
\hline & & 40 & & 1.6 & 250 & 495 \\
\hline & & 45 & & 1.8 & 265 & 495 \\
\hline & & 50 & & 2.0 & 280 & 495 \\
\hline & & 60 & & 2.4 & 310 & 495 \\
\hline & & 70 & & 2.8 & 340 & 495 \\
\hline & & 80 & & 3.2 & 370 & 495 \\
\hline & & 90 & & 3.6 & 400 & 495 \\
\hline & & 100 & & 4.0 & 430 & 495 \\
\hline & & 20 & \multirow{5}{*}{35} & 0.6 & 210 & 505 \\
\hline & & 40 & & 1.1 & 270 & 505 \\
\hline & & 60 & & 1.7 & 330 & 505 \\
\hline & & 80 & & 2.3 & 390 & 505 \\
\hline & & 100 & & 2.9 & 450 & 505 \\
\hline \multirow{9}{*}{$\begin{array}{c}\text { Effect of } \\
\text { Concrete } \\
\text { Cover } \\
(c)\end{array}$} & \multirow{9}{*}{20} & \multirow{3}{*}{20} & 10 & 2.0 & 160 & 480 \\
\hline & & & 25 & 0.8 & 190 & 495 \\
\hline & & & 35 & 0.6 & 210 & 505 \\
\hline & & \multirow{3}{*}{40} & 10 & 4.0 & 220 & 480 \\
\hline & & & 25 & 1.6 & 250 & 495 \\
\hline & & & 35 & 1.1 & 270 & 505 \\
\hline & & \multirow{3}{*}{100} & 10 & 10.0 & 400 & 480 \\
\hline & & & 25 & 4.0 & 430 & 495 \\
\hline & & & 35 & 2.9 & 450 & 505 \\
\hline
\end{tabular}




\section{$\underline{\mathrm{Du}, \text { et al-Beam Crack-Tables and Figures }}$}

Table 2 Configurations and Surfaces Cracks of Corroded Concrete Beams

\begin{tabular}{|c|c|c|c|c|c|c|}
\hline $\begin{array}{l}\text { Beam } \\
\text { NO. }\end{array}$ & Surfaces & $\begin{array}{l}\text { Cracks on Surfaces of Corroded Beams (L- } \\
\text { Longitudinal Bars, T-Transverse Links) }\end{array}$ & $\begin{array}{l}\text { Bar } \\
\mathrm{d}(\mathrm{mm})\end{array}$ & $\begin{array}{l}\text { Cover } \\
\text { c (mm) }\end{array}$ & $\begin{array}{l}\text { Distance } \\
\mathrm{s}(\mathrm{mm})\end{array}$ & $\mathbf{s} / \mathbf{c}$ \\
\hline \multirow[t]{2}{*}{$\mathrm{C} 124$} & $\begin{array}{r}\text { Side } \\
\text { (L-Cracks) }\end{array}$ & & 12 & $\begin{array}{l}20 \\
25\end{array}$ & 86 & $\begin{array}{l}4.3 \\
>2\end{array}$ \\
\hline & $\begin{array}{r}\text { Top } \\
\text { (No crack) }\end{array}$ & & \multicolumn{4}{|c|}{ External Cracking(HS) } \\
\hline \multirow[t]{2}{*}{ C162 } & \multirow{2}{*}{$\begin{array}{r}\text { Side } \\
\text { (No Crack) } \\
\text { Top } \\
\text { (L-Cracks) }\end{array}$} & & 12 & $\begin{array}{l}20 \\
17\end{array}$ & 86 & $\begin{array}{l}4.3 \\
> \\
2.2\end{array}$ \\
\hline & & 10 & \multicolumn{4}{|c|}{ External Cracking(VB) } \\
\hline \multirow[t]{2}{*}{ T322 } & $\begin{array}{r}\text { Side } \\
\text { (L-Cracks) }\end{array}$ & & 32 & $\begin{array}{l}20 \\
20\end{array}$ & 46 & $\begin{array}{c}23 \\
\approx \\
2.2\end{array}$ \\
\hline & $\begin{array}{r}\text { Bottom } \\
\text { (L-Cracks) }\end{array}$ & $\therefore$ & \multicolumn{4}{|c|}{$\begin{array}{l}\text { Internal Penetration } \\
+ \text { External Cracking (HS) \& (VB) }\end{array}$} \\
\hline \multirow[t]{2}{*}{ T164 } & $\begin{array}{r}\text { Side } \\
\text { (L-Cracks) }\end{array}$ & BEAM $=$ & $\begin{array}{c}2 @ 16= \\
32\end{array}$ & $\begin{array}{l}20 \\
20\end{array}$ & 46 & $\begin{array}{l}23 \\
\approx \\
2.2\end{array}$ \\
\hline & $\begin{array}{r}\text { Bottom } \\
\text { (L-Cracks) }\end{array}$ & & \multicolumn{4}{|c|}{$\begin{array}{l}\text { Internal Penetration } \\
+ \text { External Cracking (HS) \& (VB) }\end{array}$} \\
\hline \multirow[t]{2}{*}{ T163 } & $\begin{array}{r}\text { Side } \\
\text { (L-Cracks) }\end{array}$ & & $\begin{array}{c}2 @ 16= \\
32\end{array}$ & $\begin{array}{l}20 \\
20\end{array}$ & 46 & $\begin{array}{l}23 \\
\approx \\
2.2\end{array}$ \\
\hline & $\begin{array}{r}\text { Bottom } \\
\text { (L-Cracks) }\end{array}$ & 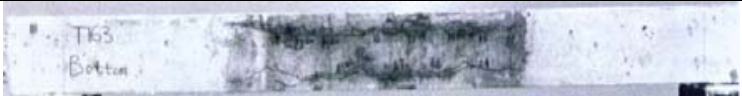 & \multicolumn{4}{|c|}{$\begin{array}{l}\text { Internal Penetration } \\
+ \text { External Cracking (HS) \& (VB) }\end{array}$} \\
\hline \multirow[t]{2}{*}{ T282 } & $\begin{array}{r}\text { Side } \\
\text { (No L } \\
\text { Cracks) } \\
\text { (T-Cracks) }\end{array}$ & & 12 & $\begin{array}{l}20 \\
20\end{array}$ & 86 & $\begin{array}{l}4.3 \\
> \\
2.2\end{array}$ \\
\hline & Bottom & & \multicolumn{4}{|c|}{ External Cracking(VB) } \\
\hline \multirow[t]{2}{*}{ T122 } & $\begin{array}{r}\text { Side } \\
\text { (No L } \\
\text { Cracks) } \\
\text { (T-Cracks) } \\
\end{array}$ & Bip Xes: & 12 & $\begin{array}{l}20 \\
20\end{array}$ & 86 & $\begin{array}{l}4.3 \\
> \\
2.2\end{array}$ \\
\hline & $\begin{array}{r}\text { Bottom } \\
\text { (L-Cracks) }\end{array}$ & & \multicolumn{4}{|c|}{ External Cracking(VB) } \\
\hline \multirow[t]{2}{*}{ R122 } & $\begin{array}{r}\text { Side } \\
\text { (No L } \\
\text { Cracks) } \\
\text { (T-Cracks) } \\
\end{array}$ & 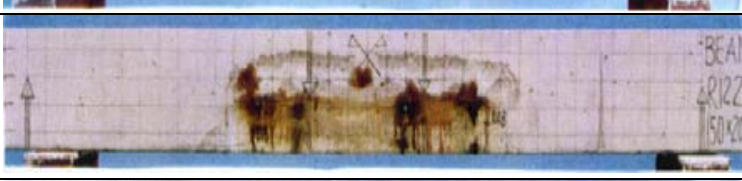 & 12 & $\begin{array}{l}20 \\
20\end{array}$ & 86 & $\begin{array}{l}4.3 \\
> \\
2.2\end{array}$ \\
\hline & $\begin{array}{r}\text { Bottom } \\
\text { (L-Cracks) }\end{array}$ & 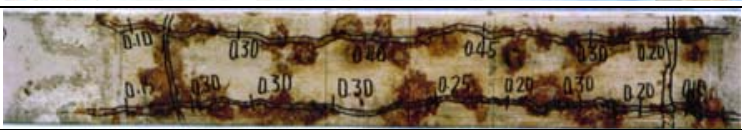 & \multicolumn{4}{|c|}{ External Cracking(VB) } \\
\hline
\end{tabular}

